\title{
Successful implantation and live birth of a healthy boy after triple biopsy and double vitrification of oocyte-embryo-blastocyst
}

\author{
Ermanno Greco ${ }^{1 *}$, Anil Biricik², Rocio P Cotarelo ${ }^{1}$, Elisabetta lammarone ${ }^{1}$, Patrizia Rubino ${ }^{1}$, Jan Tesarik ${ }^{3}$,
} Francesco Fiorentino ${ }^{2}$ and Maria Giulia Minasi ${ }^{1}$

\begin{abstract}
Introduction: Preimplantation genetic diagnosis and/or screening (PGD/PGS) allow the assessment of the genetic health of an embryo before transferring it into the uterus. These techniques require the removal of cellular material (polar bodies, blastomere(s) or trophectoderm cells) in order to perform the proper genetic analysis. We report the implantation and live birth outcome of a vitrified-warmed blastocyst developed after triple biopsy and double vitrification procedures at oocyte, cleavage embryo and blastocyst stage.

Case description: An infertile couple, with family history of $\beta$-thalassemia, searched for IVF procedure and PGD. First polar bodies biopsy with subsequent vitrification was uninformative due to meiotic crossing-over, so oocytes were inseminated after warming. Two embryos were obtained and blastomere biopsy was performed on day 3 with inconclusive results on their genetic status. Their culture resulted in one expanded blastocyst stage on day 7 that underwent trophectoderm biopsy and vitrification. This embryo showed to be normal. It was then warmed and transferred in an artificial cycle.

Discussion and Evaluation: Preconception genetic analysis by removal and analysis of the first polar body is technically possible, but the genetic information that we can obtain at this stage may be limited and the oocytes to be inseminated is not predictable. Compared to blastomere biopsy, trophectoderm biopsy has more diagnostic efficiency with respect to both chromosomal mosaicism and PCR accuracy, reducing the problems of amplification failure and allele drop out. Moreover, embryos biopsied at the cleavage stage seem to have lower implantation rate than biopsied blastocyst.

Conclusions: This is the first case report of a live birth obtained from a three step biopsy and double vitrification procedures of a blastocyst. This case report seems also to suggest the harmlessness of all these procedures if carefully performed by a skilled biologist in an IVF lab with quality management system. Finally, our study highlight that blastocyst cryopreserved on day 7 have clinically important potential and embryos that not reach blastocyst stage on day 6 should not to be discharged because they may result in an ongoing pregnancy.
\end{abstract}

Keywords: Vitrification; Polar body biopsy; Embryo biopsy; Blastocyst biopsy

\footnotetext{
* Correspondence: ergreco1@virgilio.it

'Centre for Reproductive Medicine, European Hospital, Rome, Italy

Full list of author information is available at the end of the article
} 


\section{Background}

Preimplantation genetic diagnosis and/or screening (PGD/ PGS) allow the assessment of the genetic health of an embryo before transferring it into the uterus. These techniques require the removal of cellular material in order to perform the proper genetic analysis.

Potential sources of genetic material are: first (1 PB) and second polar bodies (2 PB), day 3 embryo blastomeres, and blastocyst trophectoderm cells (Brezina et al. 2013; Greco et al. 2013). All these techniques require several laboratory manipulation procedures before embryo transfer: oocyte zona pellucida laser drilling, embryo biopsy, cryopreservation and thawing, that might affect embryo survival and its implantation potential (Scott et al. 2013a; Zhang et al. 2009).

One of the most critical point in PGD/PGS programs is assessing the right time to do the genetic analysis. In fact this issue needs careful considerations: accurate identification of the genetic status of the oocyte in case of monogenic disease especially when only the first polar body is analyzed, the possibility of mosaicism phenomenon and self correction mechanism at cleavage stage embryo, minimization of the biopsy adverse effect on the embryo (Scott et al. 2013a).

We report a normal blastocyst development and a successful live birth after sequential application of multiple potentially invasive biological micromanipulation techniques (polar body, blastomere and trophectoderm biopsy) and repeated vitrification and warming procedures.

\section{Case presentation}

An infertile couple, with family history of $\beta$-thalassemia (Galanello and Origa 2010) searched for IVF procedure and preimplantation genetic diagnosis (PGD): a 37 year old woman and a 38 year old man, carriers of the IVS1$110 \mathrm{G}>\mathrm{A}$ and the Cod $39 \mathrm{C}>\mathrm{T}$ mutations in the HBB gene (OMIM 141900), respectively. Seminal fluid examination according to the WHO recommendation (WHO 2010) showed a severe oligoastenoteratozoospermia. Ovarian reserve was evaluated combining antral follicle count (AFC), day 3 FSH and Antimullerian (AMH) dosage (Fleming et al. 2013). A written consent of the couple was obtained.

This study was approved by the Institutional Ethical Committee of the European Hospital and Genoma group. All techniques were performed according to the Helsinki declaration of 1975 and its modifications.

Controlled ovarian stimulation was performed using a long gonadotrophin-releasing hormone $(\mathrm{GnRH})$ agonist suppression protocol starting on the $21^{\text {st }}$ day of the preceding cycle until the day of triggering; recombinant FSH administration (GonalF, MerkSerono, Italy) was started on the $3^{\text {rd }}$ day of the cycle. When at least 3 follicles reached $19 \mathrm{~mm}$ in diameter, 10.000 UI hCG (Gonasi, $10.000 \mathrm{UI}$,
IBSA, Lodi, Italy) was administered by intramuscular injection (Huber et al. 2013). Thirty-six hour later, ten oocytes were retrieved through an ultrasound-guided transvaginal follicular puncture; five of them were found to be metaphase II.

Polar body analysis was chosen as the first diagnostic option for ethical reasons. Polar body biopsy consisted in opening the zona pellucida using infrared laser drilling. Using a polar body biopsy pipette, polar bodies were extracted from oocytes (Humagen, Origio, Charlostesville, VA, USA) through an hole into the perivitelline space making a gentle suction. After the biopsy oocytes were vitrified (Montag et al. 2013).

For cleavage stage, the blastomere biopsy pipette (Humagen, Origio, Charlostesville, VA, USA) was introduced inside the embryo using the same hole. After biopsy embryos were transferred to sequential culture media (Quinn's Advantage Blastocyst medium, SAGE, CooperSurgical, Pasadena, CA, USA) (Kaser and Ginsburg 2014).

For blastocyst stage, using a combination of gently suction with blastomere aspiration pipette (COOK, Ireland) and the proper number of laser pulses (each one of 3,7 intensity) (Chang et al. 2013), around 6-8 trophectoderm cells were dissected from the expanded blastocyst. The blastocyst was then vitrified.

The biopsied cells were placed in RNase-DNase-free $0.2 \mathrm{ml}$ PCR tubes using a $130 \mu \mathrm{m}$ glass pipette (Humagen, Origio, Charlostesville, VA, USA), in the same way for all three kinds of cells biopsied and sent for genetic analysis. PCR conditions used and the strategy used for mutation analysis are described elsewhere (Fiorentino et al. 2006).

Vitrification, thawing procedure and materials were the same for oocytes, embryos and blastocyst (Cryotop and Vitrification kit, Kitazato Supply, Shizuoka, Japan) (Mukaida and Oka 2012).

Five oocytes were submitted to PB biopsy and vitrification. Their genetic analysis revealed that one of the oocytes carried the mutation, three oocytes could not be diagnosed due to their recombinant state and one oocyte was excluded because was in telophase I stage and not suitable for biopsy. After a genetic counselling, the couple decided to proceed with the insemination of the three recombinant oocytes. The vitrified oocytes were warmed and the ICSI procedure was performed on the two survived, obtaining two $72 \mathrm{~h}$ cleavage stage embryos submitted to one-blastomere biopsy. Genetic analysis was uninformative, so a new biopsy was performed on the trophectoderm cells of an expanded blastocyst on day 7 immediately vitrified (Figure 1). The PCR analysis revealed that the embryo was healthy carrier for $\beta$-thalassemia and suitable for transfer.

The blastocyst was warmed and transferred on the scheduled day (Figure 2). Frozen-thawed blastocyst transfer was perfomed in an artificial cycle combining 

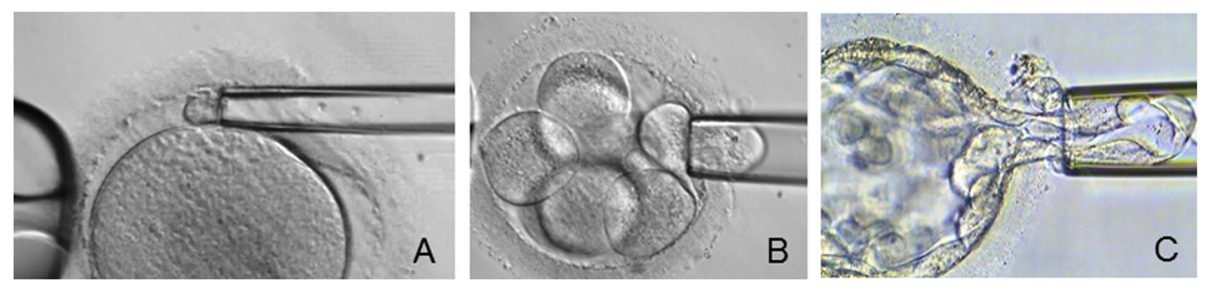

Figure 1 Polar body (A), blastomere (B) and trophectoderm (C) biopsies.

gonadotrophin-releasing hormone agonist and estrogen pill (Progynova, Bayer, New Zealand limited, Auckland). Transfer was carried under ultrasound guidance when endometrium thickness reached $8 \mathrm{~mm}$. Intramuscular administration of progesterone in oil (Prontogest, IBSA, Lodi, Italy) was initiated 5 days before embryo transfer (Hill et al. 2010).

A positive $\beta$-HCG was obtained 11 days after embryo transfer and fetal heart beat was confirmed by ultrasound observation 7 weeks after. The patient delivered an healthy boy weighting $3.900 \mathrm{~g}$ at 40 weeks of gestation. No neonatal problems have been reported.

\section{Discussion}

This is the first case report of a live birth obtained from a three step biopsy and double vitrification procedures of a blastocyst. Many biological and clinical considerations can be drawn from this case. Preconception genetic analysis by removal and analysis of the first polar body is technically possible, but the genetic information that we can obtain at this stage may be limited and the oocytes to be inseminated is not predictable. Theoretically, the biopsy and genetic analysis of the first polar body is likely to have some advantages respect to preimplantation diagnosis performed on the blastomere or trophectoderm cells. Biopsy of the oocyte prior to fertilization is ethically accepted since it does not require manipulation of the pre-embryo. Our study confirms that aspiration of the first polar body seems to have no detrimental effects on fertilization or quality of the embryonic development until to the blastocyst stage because it is not involved in all these processes (Macas et al. 2011). Different studies, on the contrary, showed that day 3 embryos that undergone blastomere biopsy had more fragmentation and showed a slower cell division if compared with unbiopsied controls, but no definitive conclusion on the safety of $\mathrm{PB}$ biopsy with respect to the embryo implantation potential is available at present because all the published studies are underpowered (Montag et al. 2013; Levin et al. 2012). Biological availability of oocytes for first polar body biopsy can also be reduced at methaphase II stage. In fact, recent investigations have demonstrated that some oocytes showing a first PB may still be in telophase I stage due to the presence of a connective spindle strand between the first $\mathrm{PB}$ and the oocyte, as occurred in the present case (Montag et al. 2006). Often vitrification of the biopsied oocytes is necessary if the genetic analysis needs time because their fertilization rate decrease if too much time intercourses between the oocytes denudation and intracytoplasmic sperm injection (Patrat et al. 2012).

Preconception diagnosis by the removal and PCR analysis of the first polar body has been successfully applied to many genetic diseases, including sickle cell anaemia
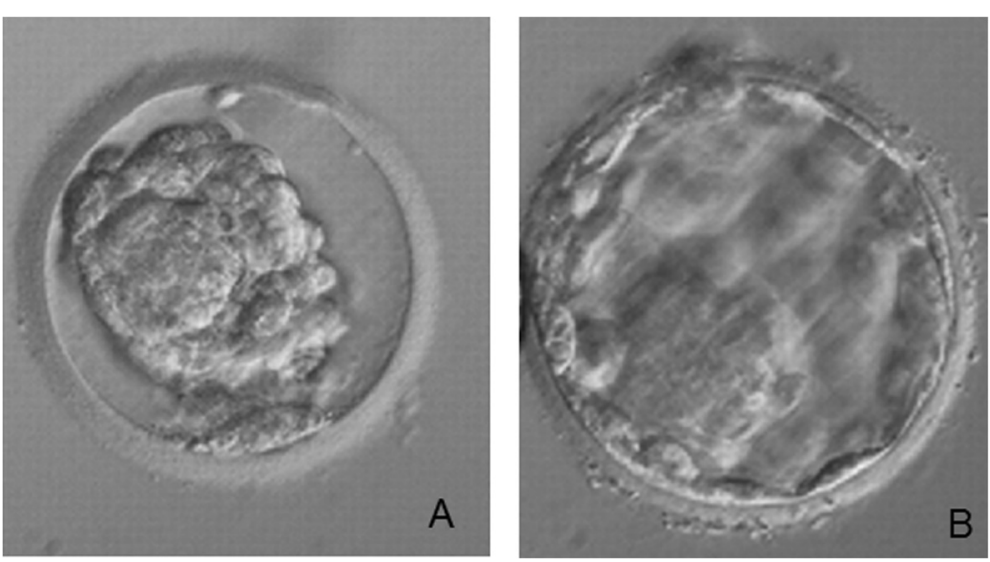

Figure 2 Day-7 biopsied blastocyst wich resulted in a healthy boy, immediately after the warming (A) and two hours after incubation before the transfer (B). 
(Saiki et al. 1985), a-thalassaemia (Saiki et al. 1985; Chehab et al. 1987), $\beta$-thalassaemia (Saiki et al. 1988), cystic fibrosis (Kerem et al. 1989), Duchenne's muscular dystrophy (Speer et al. 1989) and Tay Sach's disease (Myerowitz 1988; Myerowitz and Costigan 1988) but the possibility of crossing over between homologous chromosomes must be considered. If this occurs, the primary oocytes will be heterozygous for the abnormal gene and the genotype of the oocyte is not correctly predictable. The probability of a crossing over occurring between any gene and the centromere is a function of the distance of the gene from the centromere. For telomeric genes, crossing over occurs with sufficient frequency that the genes segregate independently from the centromere. For telomeric genes the prediction is that one quarter of aspirated polar bodies will give the correct information and consequently only one quarter of the oocytes will be suitable for the ICSI procedure. For genes situated close to the telomere, the percentage of meiosis with crossing over between the locus and the centromere will be lower (Verlinsky et al. 1990). Our results are agree with others studies in which the percentage of recombinant oocytes for beta thalassemia gene was very high (Verlinsky et al. 1997; Fiorentino et al. 2008). In these cases biopsy of both polar bodies or biopsy of blastomere at cleavage stage, if the analysis of paternally derived mutations is needed, is necessary to give complete genetic information (Kuliev and Rechitsky 2011).

Allele drop out (ADO) and amplification failure of both alleles are well known phenomena in PCR on single cells. This can depend on several reasons: the cell type employed for the PCR (Rechitsky et al. 1998), genes and markers (Dreesen et al. 1996), lysis and PCR conditions (Levinson et al. 1992; Gitlin et al. 1996; Ray et al. 1996).

Trophectoderm biopsy has more diagnostic efficiency with respect to both chromosomal mosaicism and PCR accuracy, reducing the problems of amplification failure and allele drop out (Chang et al. 2013; Yang et al. 2013). Moreover we have to consider the effect of biopsy on implantation at cleavage stage embryos. A recent randomized controlled trial demonstrated that embryos biopsied at the cleavage stage have lower implantation rate than biopsied blastocyst (Goossens et al. 2008; Scott et al. 2013b).

In a recent publication is demonstrated that blastocyst cryopreserved on day 7 have lower but clinically important potential, as in our study (Kovalevsky et al. 2013). For this reason, embryos that not reach blastocyst stage on day 6 should not to be discharged because they may result in an ongoing pregnancy.

Cryopreservation of oocytes, embryos and blastocysts is currently used technique in reproductive medicine (Chhabra and Kutchi 2013; Cobo et al. 2011; Bhattacharya and Kamath 2013). Attempts of using conventional slow- freezing protocols in PGD programs have shown not to be successful, since the lack of the intact zona pellucida protection causes crystal formation that implies extensive damage after thawing. Vitrification protocols, reducing the formation of intracellular ice crystals provides better protection from cryoinjury (AbdelHafez et al. 2010). Different clinical studies have demonstrated both high survival rates of frozen thawed oocytes, embryos and high implantation rates and live births of euploid biopsied blastocysts (Borini et al. 2008). Our study seems also to suggest the harmlessness of all these procedures if carefully performed by a skilled biologist in an IVF lab with quality management system (Practice Committees of ASRM 2013).

\section{Competing interests}

The authors declare that they have no competing interests. The authors declare that they have no "non-financial competing interests" (political, personal, religious, ideological, academic, intellectual, commercial or any other) to declare in relation to this manuscript.

\section{Authors' contributions}

EG was involved in study conception and design, data interpretation, drafting manuscript and final approval. AB was involved in genetic analysis and interpretation of data. RPC was involved in drafting the manuscript and took part in the laboratory procedures, critical discussion and final approval. El took part in stimulation protocols, surgical procedures and final approval. PR took part in the laboratory procedures and final approval. JT provided a critical discussion, extensive improvement of the manuscript and final approval. FF was involved in genetic analysis of results, in the critical revision of the article and final approval. MGM was involved in all laboratory procedures, in the acquisition of data, critical revision of the article and final approval. All authors read and approved the final manuscript.

\section{Acknowledgement}

The authors thank Dr. Valentina Casciani, PhD, and Dr. Alessandro Colasante, $\mathrm{PhD}$, for their critical revision of the manuscript. No funding for authors and for the manuscript preparation were obtained.

\section{Author details}

${ }^{1}$ Centre for Reproductive Medicine, European Hospital, Rome, Italy. ${ }^{2}$ Genoma, Molecular Genetics Laboratory, Rome, Italy. ${ }^{3}$ MAR\&Gen Clinic, Molecular

Assisted Reproduction and Genetics, Granada, Spain.

Received: 22 October 2014 Accepted: 2 January 2015

Published online: 14 January 2015

\section{References}

AbdelHafez FF, Desai N, Abou-Setta AM, Falcone T, Goldfarb J (2010) Slow freezing, vitrification and ultra-rapid freezing of human embryos: a systematic review and meta-analysis. Reprod Biomed Online 20(2):209-222, doi:10.1016/j.rbmo. 2009.11.013

Bhattacharya S, Kamath MS. Reducing multiple births in assisted reproduction technology. Best Pract Res Clin Obstet Gynaecol. 2013. 4. doi:10.1016/j. bpobgyn.2013.11.005

Borini A, Cattoli M, Bulletti C, Coticchio G (2008) Clinical efficiency of oocyte and embryo cryopreservation. Ann N Y Acad Sci 1127:49-58, doi:10.1196/ annals. 1434.012

Brezina PR, Ke RW, Kutteh WH (2013) Preimplantation genetic screening: a practical guide. Clin Med Insights Reprod Health 7:37-42, doi:10.4137/CMRH. S10852

Chang $\sqcup$, Huang CC, Tsai YY, Hung CC, Fang MY, Lin YC, Su YN, Chen SU, Yang YS (2013) Blastocyst biopsy and vitrification are effective for preimplantation genetic diagnosis of monogenic diseases. Hum Reprod 28(5):1435-1444, doi:10.1093/humrep/det048

Chehab FF, Doherty M, Cai SP, Kan YW, Cooper S, Rubin EM (1987) Detection of sickle cell anaemia and thalassaemias. Nature 329(6137):293-294, PMID:3627274 
Chhabra S, Kutchi I (2013) Fertility Preservation in Gynecological Cancers. Clin Med Insights Reprod Health 7:49-59, PMID:24453519

Cobo A, Remohí J, Chang CC, Nagy ZP (2011) Oocyte cryopreservation for donor egg banking. Reprod Biomed Online 23(3):341-346, doi:10.1016/j.rbmo.2011. 05.014

Dreesen JC, Bras M, Coonen E, Dumoulin JC, Evers JL, Geraedts JP (1996) Allelic dropout caused by allele-specific amplification failure in single-cell PCR of the cystic fibrosis delta F508 deletion. J Assist Reprod Genet 13(2):112-114, PMID:8688582

Fiorentino F, Biricik A, Nuccitelli A, De Palma R, Kahraman S, lacobelli M, Trengia V, Caserta D, Bonu MA, Borini A, Baldi M (2006) Strategies and clinical outcome of 250 cycles of Preimplantation Genetic Diagnosis for single gene disorders. Hum Reprod 21(3):670-684, PMID:16311287

Fiorentino F, Biricik A, Nuccitelli A, De Palma R, Kahraman S, Sertyel S, Karadayi H, Cottone G, Baldi M, Caserta D, Moscarini M (2008) Rapid protocol for pre-conception genetic diagnosis of single gene mutations by first polar body analysis: a possible solution for the Italian patients. Prenat Diagn 28(1):62-64, PMID:18058979

Fleming R, Broekmans F, Calhaz-Jorge C, Dracea L, Alexander H, Nyboe AA, Blockeel C, Jenkins J, Lunefeld B, Platteau P, Smitz J, de Ziegler D (2013) Can anti-Mullerian hormone concentration be used to determine gonadotrophin dose and treatment protocol for ovarian stimulation? Reprod Biomed Online 26(5):431-439, doi:10.1016/j.rbmo.2012.02.027

Galanello R, Origa R (2010) Beta-thalassemia. Orphanet J Rare Dis 21:5-11, doi:10.1186/1750-1172-5-11

Gitlin SA, Lanzendorf SE, Gibbons WE (1996) Polymerase chain reaction amplification specificity: incidence of allele dropout using different DNA preparation methods for heterozygous single cells. J Assist Reprod Genet 13(2):107-111, PMID:8688581

Goossens V, De Rycke M, De Vos A, Staessen C, Michiels A, Verpoest W, Van Steirteghem A, Bertrand C, Liebaers I, Devroey P, Sermon K (2008) Diagnostic efficiency, embryonic develop ment and clinical outcome after the biopsy of one or two blastomeres for preimplantation genetic diagnosis. Hum Reprod 23(3):481-9212, PMID: 18156649

Greco E, Fabozzi G, Ruberti A, Zavaglia D, Minasi MG (2013) Preimplantation genetic diagnosis and the biopsy technique: Important considerations. Advances in Reproductive Sciences 1:7-14, doi:10.4236/arsci.2013.12002

Hill MJ, Miller KA, Frattarelli JL (2010) A GnRH agonist and exogenous hormone stimulation protocol has a higher live-birth rate than a natural endogenous hormone protocol for frozen-thawed blastocyst-stage embryo transfer cycles: an analysis of 1391 cycles. Fertil Steril 93(2):416-422, doi:10.1016/j.fertnstert. 2008.11.027

Huber M, Hadziosmanovic N, Berglund L, Holte J (2013) Using the ovarian sensitivity index to define poor, normal, and high response after controlled ovarian hyperstimulation in the long gonadotropin-releasing hormoneagonist protocol: suggestions for a new principle to solve an old problem. Fertil Steril 100(5):1270-1276, doi:10.1016/j.fertnstert.2013.06.049

Kaser DJ, Ginsburg ES (2014) Embryo biopsy for aneuploidy detection in the general infertility population. Semin Reprod Med 32(2):100-106, doi:10.1055/ s-0033-1363551

Kerem B, Rommens JM, Buchanan JA, Markiewicz D, Cox TK, Chakravarti A, Buchwald M, Tsui LC (1989) Identification of the cystic fibrosis gene: genetic analysis. Science 245(4922):1073-1080, PMID:2570460

Kovalevsky G, Carney SM, Morrison LS, Boylan CF, Neithardt AB, Feinberg RF (2013) Should embryos developing to blastocysts on day 7 be cryopreserved and transferred: an analysis of pregnancy and implantation rates. Fertil Steril 100(4):1008-1012, doi:10.1016/j.fertnstert.2013.06.021

Kuliev A, Rechitsky S (2011) Polar body-based preimplantation genetic diagnosis for Mendelian disorders. Mol Hum Reprod 17(5):275-285, doi:10.1093/ molehr/gar012

Levin I, Almog B, Shwartz T, Gold V, Ben-Yosef D, Shaubi M, Amit A, Malcov M (2012) Effects of laser polar-body biopsy on embryo quality. Fertil Steril 97(5):1085-1088, doi:10.1016/j.fertnstert.2012.02.008

Levinson G, Fields RA, Harton GL, Palmer FT, Maddalena A, Fugger EF, Schulman JD (1992) Reliable gender screening for human preimplantation embryos, using multiple DNA target-sequences. Hum Reprod 7(9):1304-1313, PMID:1479016

Macas E, Xie M, Schaufelberger S, Merki-Feld GS, Stiller R, Imthurn B (2011) Vitrification of human single pronuclear oocytes following two approaches to polar body biopsy. Reprod Biomed Online 22(4):376-381, doi:10.1016/j. rbmo.2011.01.004
Montag M, Schimming T, van der Ven H (2006) Spindle imaging in human oocytes: the impact of the meiotic cell cycle. Reprod Biomed Online 12(4):442-446, PMID:16740216

Montag M, Köster M, Strowitzki T, Toth B (2013) Polar body biopsy. Fertil Steril 100(3):603-607, doi:10.1016/j.fertnstert.2013.05.053

Mukaida T, Oka C (2012) Vitrification of oocytes, embryos and blastocysts. Best Pract Res Clin Obstet Gynaecol 26(6):789-803, doi:10.1016/j. bpobgyn.2012.07.001

Myerowitz R (1988) Splice junction mutation in some Ashkenazi Jews with Tay-Sachs disease: evidence against a single defect within this ethnic group. Proc Natl Acad Sci U S A 85(11):3955-3959, PMID:3375249

Myerowitz R, Costigan FC (1988) The major defect in Ashkenazi Jews with Tay-Sachs disease is an insertion in the gene for the alpha-chain of betahexosaminidase. J Biol Chem 263(35):18587-18589, PMID:2848800

Patrat C, Kaffel A, Delaroche L, Guibert J, Jouannet P, Epelboin S, De Ziegler D, Wolf JP, Fauque P (2012) Optimal timing for oocyte denudation and intracytoplasmic sperm injection. Obstet Gynecol Int 2012:403531, doi:10.1155/2012/403531

Practice Committees of the American Society for Reproductive Medicine and the Society for Assisted Reproductive Technology (2013) Blastocyst culture and transfer in clinical-assisted reproduction: a committee opinion. Fertil Steril 99 (3):667-672, doi:10.1016/j.fertnstert.2013.01.087

Ray PF, Winston RM, Handyside AH (1996) Reduced allele dropout in single-cell analysis for preimplantation genetic diagnosis of cystic fibrosis. J Assist Reprod Genet 13(2):104-106, PMID:8688580

Rechitsky S, Strom C, Verlinsky O, Amet T, Ivakhnenko V, Kukharenko V, Kuliev A, Verlinsky Y (1998) Allele dropout in polar bodies and blastomeres. J Assist Reprod Genet 15(5):253-257, PMID:9604756

Saiki RK, Scharf S, Faloona F, Mullis KB, Horn GT, Erlich HA, Arnheim N (1985) Enzymatic amplification of beta-globin genomic sequences and restriction site analysis for diagnosis of sickle cell anemia. Science 230(4732):1350-1354, PMID:2999980

Saiki RK, Chang CA, Levenson CH, Warren TC, Boehm CD, Kazazian HH Jr, Erlich HA (1988) Diagnosis of sickle cell anemia and beta-thalassemia with enzymatically amplified DNA and nonradioactive allele-specific oligonucleotide probes. N Engl J Med 319(9):537-541, PMID:3405266

Scott KL, Hong KH, Scott RT Jr (2013a) Selecting the optimal time to perform biopsy for preimplantation genetic testing. Fertil Steril 100(3):608-614, doi:10.1016/j.fertnstert.2013.07.004

Scott RT Jr, Upham KM, Forman EJ, Zhao T, Treff NR (2013b) Cleavage-stage biopsy significantly impairs human embryonic implantation potential while blastocyst biopsy does not: a randomized and paired clinical trial. Fertil Steril 100(3):624-630, doi:10.1016/j.fertnstert.2013.04.039

Speer A, Rosenthal A, Billwitz H, Hanke R, Forrest SM, Love D, Davies KE, Coutelle C (1989) DNA amplification of a further exon of Duchenne muscular dystrophy locus increase possibilities for deletion screening. Nucleic Acids Res 17(12):4892, PMID:2783234

Verlinsky Y, Ginsberg N, Lifchez A, Valle J, Moise J, Strom CM (1990) Analysis of the first polar body: preconception genetic diagnosis. Hum Reprod 5(7):826-829, PMID:2266156

Verlinsky Y, Rechitsky S, Cieslak J, Ivakhnenko V, Wolf G, Lifchez A, Kaplan B, Moise J, Walle J, White M, Ginsberg N, Strom C, Kuliev A (1997) Preimplantation diagnosis of single gene disorders by two-step oocyte genetic analysis using first and second polar body. Biochem Mol Med 62(2):182-187, PMID:9441871

World Health Organization (2010) WHO laboratory manual for the examination and processing of human semen, 5th edn. Cambridge University Press, Cambridge

Yang Z, Salem SA, Liu X, Kuang Y, Salem RD, Liu J (2013) Selection of euploid blastocysts for cryopreservation with array comparative genomic hybridization $(\mathrm{aCGH})$ results in increased implantation rates in subsequent frozen and thawed embryo transfer cycles. Mol Cytogenet 6(1):32, doi:10.1186/1755-8166-6-32

Zhang X, Trokoudes KM, Pavlides C (2009) Vitrification of biopsied embryos at cleavage, morula and blastocyst stage. Reprod Biomed Online 19(4):526-531, PMID:19909594 